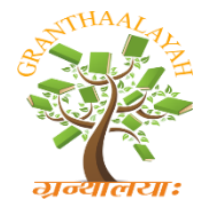

INTERNATIONAL JOURNAL OF RESEARCH GRANTHAALAYAH A knowledge Repository

Social

\title{
CLASSROOM CLIMATE AND ACHIEVEMENT MOTIVATION OF HIGHER SECONDARY SCHOOL STUDENTS IN KANYAKUMARI DISTRICT
}

\author{
Sutha.M"1, Dr. Shirlin. $\mathbf{P}^{2}$ \\ ${ }^{* 1}$ MEd Scholar, M.E.T College of Education, Chenbagaramanputhur, India \\ ${ }^{2}$ Assistant Professor, M.E.T College of Education, Chenbagaramanputhur, India
}

DOI: https://doi.org/10.29121/granthaalayah.v5.i3(SE).2017.1931

\begin{abstract}
The present study was conducted to know the Classroom climate and Achievement motivation of higher secondary school students in Kanyakumari District. The investigator collected data from 420 higher secondary school students by stratified random sampling method. Classroom Climate Inventory and Achievement Motivation Scales were used as tools. The data obtained were analysed by using appropriate statistical techniques like t-test, ANOVA and correlation. The obtained results showed that there exists a significant substantial correlation between Classroom climate and Achievement motivation of higher secondary school students. Achievement motivation based on the medium of instruction of higher secondary school students found to be significantly higher than English medium students.
\end{abstract}

Keywords: Classroom; Achievement; Motivation; Secondary School \& Students.

Cite This Article: Sutha.M, and Dr. Shirlin. P. (2017). "CLASSROOM CLIMATE AND ACHIEVEMENT MOTIVATION OF HIGHER SECONDARY SCHOOL STUDENTS IN KANYAKUMARI DISTRICT." International Journal of Research - Granthaalayah, 5(3)SE, 23-32. https://doi.org/10.29121/granthaalayah.v5.i3(SE).2017.1931.

\section{Introduction}

Focus on education outcomes has increased in the past decade with state wide high testing and nationwide school accountability programmes. In an effort to improve the academic success of students, it has become necessary to examine all components of the educational process in order to maximize the effectiveness of instruction within the class room to enhance the learning process and affect academic out comes (Kune 1992, Osterman 2000). Further Classroom climate and achievement motivation have been emerging as important components of education (Hacrtel and others, 1981). 
Classroom climate is defined as the type of environment that is created for students by the school, teachers, and peers which as encompasses all the socio-psychological dimensions of class room life. This includes common interest and the pursuit of common goal achieved through focused, organized and well planned lessons. The physical arrangement of the classroom furniture, the availability of resource materials, length of the class period (Chapin and Eastman 1996) and type and pace of instruction (wang and others, 1992) were also considered to influence the climate of the classroom. In sum, all events and influences within the classroom, including classroom management, comprised the construct of classroom climate (Gottfredson and goffredson 1989) Teachers are continually looking to create a "Positive" Classroom climate in which student learning is maximized. A positive classroom climate allows for students to meet their basic needs of physical and mental while there is no specific definition of what creates a negative classroom climate, it is considered to be one in which students feel uncomfortable, whether physically, emotionally, or academically, for any reason.

Achievement motivation can be defined as the need for success or the attainment of excellence. Individuals will satisfy their needs through different means, and are driven to succeed for varying reasons both internal and external Achievement motivation is a habitual desire to achieve goals through ones individual efforts, with an emphasis on establishing realistic goals, mastering the tasks needed to achieve these goals, discovering solutions to problems encountered in striving to reach these goals, and then being open to and even seeking out feedback on one's performance. Achievement motivation is based on success and achieving all of our aspirations in life. Achievement goals can affect the way a person performs a task and represent a desire to show competence (Harackiowicz and other 1997)

\section{Need and Significant of the Study}

Classroom climate is very important to promote positive learning and stimulate students who want to learn. The classroom climate needs to address all types of learning styles. The room needs to be clean and the desks need to be arranged in an orderly fashion to encourage student participation. Without a good classroom climate no one can teach effectively. One teacher may work best in a very structured classroom while another may prefer a more laid back approach. In either instance the teacher must be willing and able to insure that there is no interference with the learning process.

The achievement motivation is influenced by individual's wishes for what they want to achieve, their interest, experiences, personality patterns, personal values, sex, socio economic status and even by caste background, there are many environmental factors such as parental ambitions, social expectation, peer pressures, sex, appropriateness of aspiration, cultural traditional. Social values and competition which influence the achievement motivation

Higher secondary is a stage where the students can improve their learning styles. A good classroom climate plays a vital role in enhancing the achievement motivation of these students. 


\section{Review of Related Literature}

Chamendeswari [2008] conducted a study on "Achievement motivation and classroom climate among students at the higher secondary level". The population of this study includes students in different categories of school following different systems of education at the higher secondary level from the population sample of 300 students was taken and achievement motivational scale comprising of 40 items and scores ranging from 40 to 120 and classroom climate questionnaire comprising of 50 to 250 was used to collect data. Findings reveal that there showed a significant difference in achievement motivation and classroom climate among student in different categories of schools of the higher secondary level.

Suvin[2009] conducted a study on impact of classroom climate on the academic achievement of higher secondary students. The objectives were, to find out the significance of difference in the perceived classroom climate and academic achievement of students in terms of sex, locality, class, religion, type of management, class size and monthly income. Normative survey method was used. The sample consisted of 400 higher secondary students in various schools. The tools used were classroom inventory and achievement test marks. Statistical techniques such as mean, standard deviation, $\mathrm{t}$-test and correlation were used. The findings showed that females perceived higher level of classroom climate, when compared to male students. Government school students felt higher level of classroom climate when compared to private school students. Private school students had higher level of achievement when compared to government school students.

Manoharan and Meenakshisundaram [2003] made a study based on "Certain school variables as related to classroom climate and teachers effectiveness as perceived by higher secondary students". In objectives were (1) to find out any significant difference in classroom climate as perceived by students in terms of personal variables (2) to find out any relationship between classroom climate and teaching effectiveness as perceived by students. Samples were 410 students in standard VIII of Dindigul District by simple random sampling method. Tools employed were (1) classroom climate scale constructed and standardized by Pandya and Shefat(2) rating scale for student evaluation of teaching effectiveness constructed and standardized by Balachandran and Vedanayagam (1981) Results showed that there was significant and moderate relationship between classroom climate and teachers teaching effectiveness as perceived by students.

The study made by Pandy and Pratap [2001] based on "Achievement motivation, adjustment, anxiety and educational achievement of working and non - working mother's children" It was concluded that significant difference noted in adjustment and anxiety between working and nonworking mother's children. But no difference was found in achievement motivation and educational achievement.

\section{Statement of the Problem}

The investigator has selected the problem "Classroom climate and Achievement motivation of higher secondary school Students in Kanyakumari District". 


\section{Objectives of the Study}

1) To find out the relationship between classroom climate and achievement motivation of higher secondary school students.

2) To find out whether there is any difference in the classroom climate of higher secondary school students, with regard to the demographic variables viz., gender, locality and medium of instruction.

3) To find out whether there is any difference in the classroom climate of higher secondary school students, with regard to the demographic variables viz., religion, father's occupation and mother's occupation

4) To find out whether there is any difference in the Achievement motivation of higher secondary school students, with regard to the demographic variables viz., gender, locality and medium of instruction.

5) To find out whether there is any difference in the Achievement motivation of higher secondary school students, with regard to the demographic variables viz., religion, father's occupation and mother's occupation.

\section{Hypotheses of the Study}

1) There is no significant correlation between classroom climate and achievement motivation of higher secondary school students.

2) There is no significant difference in the classroom climate of higher secondary school students, with regard to the demographic variables viz., gender, locality and medium of instruction.

3) There is no significant difference in the classroom climate of higher secondary school students, with regard to the demographic variables viz., religion, father's occupation and mother's occupation.

4) There is no significant difference in the achievement motivation of higher secondary school students, with regard to the demographic variables viz., gender, locality and medium of instruction.

5) There is no significant difference in achievement motivation of higher secondary school students, with regard to the demographic variables viz., religion, father's occupation and mother's occupation.

\section{Methodology}

\section{Method}

The investigator adopted normative survey method of research to study the problem.

\section{Population}

The population of the present study was all the higher secondary school students of the various schools located in Kanyakumari District.

\section{Sample of the Study}

The sample of the study comprised 420higher secondary school students in Kanyakumari District. The students were selected by using stratified random sampling technique. 


\section{Tool used}

The following tools were used to measure the variable of the study.

- Achievement motivation Scale (Sam Sananda Raj and .Muthu2011)

- Classroom climate Inventory (Shirlin and Sutha, 2017).

\section{Statistical Techniques used}

In order to analyses and interpret data the following statistical measures used

- Descriptive analysis - Mean, Standard Deviation

- Differential analysis - ' $t$ ' test and ' $F$ ' test

- Relational analysis - Pearson's Product Moment Correlation

\section{Analysis and Interpretation of Data}

For analysis and interpretation of data, the study has been analysed in different tables.

\section{Hypothesis 1:}

There is no significant correlation between Classroom climate and Achievement motivation of higher secondary school students.

The extend of relationship between Classroom climate and Achievement motivation of higher secondary school students was found using correlation on a sample of 420 higher secondary school students

Table 1: Data and results of correlation between classroom climate and achievement motivation of higher secondary school students

\begin{tabular}{|l|l|l|l|l|}
\hline \multicolumn{1}{|c|}{$\begin{array}{c}\text { Variables } \\
\text { correlated }\end{array}$} & \multicolumn{1}{|c|}{$\mathbf{N}$} & \multicolumn{1}{c|}{$\mathbf{R}$} & \multicolumn{1}{c|}{$\begin{array}{c}\text { Verbal } \\
\text { Interpretation }\end{array}$} & $\begin{array}{c}\text { Level of } \\
\text { Significant }\end{array}$ \\
\hline $\begin{array}{l}\text { Classroom climate } \\
\text { and Achievement } \\
\text { motivation }\end{array}$ & 420 & 0.592 & $\begin{array}{l}\text { Substantial } \\
\text { correlation }\end{array}$ & 0.01 \\
\hline
\end{tabular}

Table 1 indicates that the Correlation between classroom climate and achievement motivation obtained on a sample of 420 higher secondary school students. Since the calculated $r$ value (0.592) is greater than the table value 0.115 at 0.01 level, it is inferred that there is a significant positive substantial correlation between classroom climate and achievement motivation of higher secondary school students. Therefore, on the basis of the results given in the Table 1 Hypothesis 1 which stated that, "There is no significant correlation between classroom climate and achievement motivation of higher secondary school students", was not accepted.

\section{Hypothesis 2:}

There is no significant difference in the classroom climate of higher secondary school students, with regard to the demographic variables viz., gender, locality and medium of instruction. 
The difference between gender, locality and medium of instruction in their classroom climate was found using t-test on a sample of 420 higher secondary school students.

Table 2: Data and results of t-test, Comparison of classroom climate of higher secondary school students based on the demographic variables between gender, locality and medium of instruction

\begin{tabular}{|c|c|c|c|c|c|c|}
\hline S.No. & \multicolumn{2}{|c|}{ Classroom climate } & $\mathbf{N}$ & Mean & S D & 't' value \\
\hline \multirow[b]{2}{*}{1} & \multirow[b]{2}{*}{ Gender } & Male & 190 & 126.18 & 19.357 & \multirow[b]{2}{*}{$6.346(\mathrm{~S})$} \\
\hline & & Female & 230 & 138.96 & 21.476 & \\
\hline \multirow{2}{*}{2} & \multirow[b]{2}{*}{ Locality } & Rural & 227 & 133.52 & 22.363 & \multirow{2}{*}{$0.353(\mathrm{NS})$} \\
\hline & & Urban & 193 & 132.78 & 20.457 & \\
\hline \multirow[b]{2}{*}{3} & \multirow{2}{*}{$\begin{array}{l}\text { Medium of } \\
\text { instruction }\end{array}$} & Tamil & 216 & 135.34 & 24.330 & \multirow[b]{2}{*}{$2.133(\mathrm{~S})$} \\
\hline & & English & 204 & 130.89 & 17.766. & \\
\hline
\end{tabular}

$\mathrm{S}$ - significant, N.S - not significant

Table 2 has shown that the obtained' $t$ ' value for the variable classroom climate of the higher secondary school students in terms of their locality $(\mathrm{t}=0.353)$ is less than table value 1.96 at 0.05 level of significance. Hence it can be inferred that the higher secondary school students do not differ in their classroom climate with respect to the locality. Therefore, hypothesis 2 is accepted.

Table 2 has also shown that the obtained ' $t$ ' value for the variable classroom climate of the higher secondary school students in terms of their gender $(t=6.346)$ and medium of instruction $(\mathrm{t}=2.133)$ are greater than table value 1.96 at 0.05 level of significance. Hence it can be inferred that the higher secondary school students differ in their classroom climate with respect to the gender and medium of instruction. Therefore, hypothesis 2 is not accepted.

\section{Hypothesis 3:}

There is no significant difference in the classroom climate of higher secondary school students, with regard to the demographic variables viz., religion, father's occupation and mother's occupation.

The differences among religion, father's occupation and mother's occupation in their classroom climate was found using ANOVA on a sample of 420higher secondary school students.

Table 3: Data and results of ANOVA, Comparison of classroom climate of higher secondary school students based on the demographic variables religion, father's occupation and mother's occupation

\begin{tabular}{|l|l|l|l|l|l|l|}
\hline S.No. & \multicolumn{2}{|c|}{ Classroom climate } & \multicolumn{1}{c|}{ SS } & \multicolumn{1}{c|}{ Df } & \multicolumn{1}{c|}{ MS } & \multicolumn{1}{c|}{ F } \\
\hline \multirow{2}{*}{1} & \multirow{2}{*}{ Religion } & Between Groups & 5045.901 & 2 & 2522.950 & \\
\cline { 3 - 7 } & & Within Groups & 188383.706 & 417 & 451.759 & $5.585(\mathrm{~S})$ \\
\hline
\end{tabular}




\begin{tabular}{|l|l|l|l|l|l|l|}
\hline \multirow{2}{*}{2} & \multirow{2}{*}{$\begin{array}{l}\text { Father's } \\
\text { occupation }\end{array}$} & Between Groups & 4727.535 & 3 & 1575.845 & \multirow{2}{*}{3.474 (S) } \\
\cline { 3 - 6 } 3 & Within Groups & 188702.073 & 416 & 453.611 & \\
\hline \multirow{2}{*}{3} & $\begin{array}{l}\text { Mother's } \\
\text { occupation }\end{array}$ & Between Groups & 1235.132 & 4 & 308.783 & \multirow{2}{*}{0.667 (NS) } \\
\cline { 3 - 6 } & & Within Groups & 192194.475 & 415 & 463.119 & \\
\hline
\end{tabular}

$\mathrm{S}$ - significant, N.S - not significant

Table 3 has shown that the obtained ' $F$ ' value for the variable classroom climate of the higher secondary school students in terms of their mother's occupation $(\mathrm{F}=0.667)$ is less than table value 2.63 at 0.05 level of significance. Hence it can be inferred that the higher secondary school students do not differ in their classroom climate with respect to the mother's occupation. Therefore, hypothesis 3 is accepted.

Table 3 has also shown that the obtained ' $F$ ' value for the variable classroom climate of the higher secondary school students in terms of their religion $(\mathrm{F}=5.568)$ and father's occupation $(\mathrm{F}=3.474)$ are greater than table value 2.63 at 0.05 level of significance. Hence it can be inferred that the higher secondary school students differ in their classroom climate with respect to the religion and father's occupation. Therefore, hypothesis 3 is not accepted.

\section{Hypothesis 4:}

There is no significant difference in the Achievement motivation of higher secondary school students with regard to the demographic variables viz., gender, locality and medium of instruction.

The difference between gender, locality and medium of instruction in their Achievement motivation was found using t-test on a sample of 420 higher secondary school students.

Table 4: Data and results of t-test, Comparison of Achievement motivation of higher secondary school students based on the demographic variables between gender, locality and medium of instruction

\begin{tabular}{|c|c|c|c|c|c|c|}
\hline S.No. & \multicolumn{2}{|c|}{ Achievement motivation } & $\mathbf{N}$ & Mean & S D & 't' value \\
\hline \multirow{2}{*}{1} & \multirow{2}{*}{ Gender } & Male & 190 & 77.55 & 12.063 & \multirow{2}{*}{$5.076(\mathrm{~S})$} \\
\hline & & Female & 230 & 84.02 & 13.730 & \\
\hline \multirow{2}{*}{2} & \multirow{2}{*}{ Locality } & Rural & 227 & 81.29 & 13.220 & \multirow{2}{*}{$0.332(\mathrm{NS})$} \\
\hline & & Urban & 193 & 80.85 & 13.600 & \\
\hline \multirow[b]{2}{*}{3} & \multirow{2}{*}{$\begin{array}{l}\text { Medium of } \\
\text { instruction }\end{array}$} & Tamil & 216 & 83.86 & 14.268 & \multirow{2}{*}{$4.464(\mathrm{~S})$} \\
\hline & & English & 204 & 78.16 & 11.712 & \\
\hline
\end{tabular}

S - significant, N.S - not significant 
Table 4 has shown that the obtained ' $t$ ' value for the variable achievement motivation of the higher secondary school students in terms of their locality $(\mathrm{t}=0.332)$ is less than table value 1.96 at 0.05 level of significance. Hence it can be inferred that the higher secondary school students do not differ in their achievement motivation with respect to the locality. Therefore, hypothesis 4 is accepted.

Table 4 has also shown that the obtained ' $t$ ' value for the variable achievement motivation of the higher secondary school students in terms of their gender $(t=5.076)$ and medium of instruction $(\mathrm{t}=4.464)$ are greater than table value 1.96 at 0.05 level of significance. Hence it can be inferred that the higher secondary school students differ in their achievement motivation with respect to the gender and medium of instruction. Therefore, hypothesis 4 is not accepted.

\section{Hypothesis 5:}

There is no significant difference in the Achievement motivation of higher secondary school students with regard to the demographic variables viz., religion, father's occupation and mother's occupation.

The difference between religion, father's occupation and mother's occupation in their Achievement motivation was found using ANOVA on a sample of 420higher secondary school students.

Table 5: Data and results of ANOVA, Comparison of Achievement motivation of higher secondary school students based on the demographic variables religion, father's occupation and mother's occupation

\begin{tabular}{|l|l|l|l|l|l|l|}
\hline S.No. & \multicolumn{2}{|c|}{ Achievement Motivation } & \multicolumn{1}{c|}{ SS } & \multicolumn{1}{c|}{ Df } & \multicolumn{1}{|c|}{ MS } & \multicolumn{1}{|c|}{ F } \\
\hline \multirow{2}{*}{1} & \multirow{2}{*}{ Religion } & Between Groups & 2696.840 & 2 & 1348.420 & \multirow{2}{*}{$7.774(\mathrm{~S})$} \\
\cline { 3 - 6 } & & Within Groups & 72329.722 & 417 & 173.453 & \\
\hline \multirow{2}{*}{2} & \multirow{2}{*}{$\begin{array}{l}\text { Father's } \\
\text { occupation }\end{array}$} & Between Groups & 2653.640 & 3 & 884.547 & \multirow{2}{*}{$5.084(\mathrm{~S})$} \\
\cline { 3 - 6 } 3 & \multirow{2}{*}{$\begin{array}{l}\text { Mother's } \\
\text { occupation }\end{array}$} & Within Groups & 72372.922 & 416 & 173.973 & \\
\cline { 3 - 6 } & & Wetween Groups & 966.573 & 4 & 241.643 & \multirow{2}{*}{$1.354(\mathrm{NS})$} \\
\hline
\end{tabular}

$\mathrm{S}$ - significant, N.S - not significant

Table 5 has shown that the obtained ' $F$ ' value for the variable achievement motivation of the higher secondary school students in terms of their mother's occupation $(F=1.354)$ is less than table value 2.63 at 0.05 level of significance. Hence it can be inferred that the higher secondary school students do not differ in their achievement motivation with respect to the mother's occupation. Therefore, hypothesis 5 is accepted.

Table 5 has also shown that the obtained ' $F$ ' value for the variable achievement motivation of the higher secondary school students in terms of their religion $(F=7.774)$ and father's occupation 
$(\mathrm{F}=5.084)$ are greater than table value 2.63 at 0.05 level of significance. Hence it can be inferred that the higher secondary school students differ in their achievement motivation with respect to the religion and father's occupation. Therefore, hypothesis 5 is not accepted.

\section{Findings of the Study}

- There exists a significant substantial correlation between classroom climate and achievement motivation.

- There exists significant difference between male and female higher secondary school students in their classroom climate and achievement motivation.

- There is no significant difference between Rural and Urban higher secondary school students in their classroom climate and achievement motivation.

- There exists significant difference between Tamil medium and English medium higher secondary school students in their classroom climate and achievement motivation.

- There exists significant difference among Hindu, Christian and Muslim higher secondary school students in their classroom climate and achievement motivation.

- There exists significant difference among higher secondary school students in their classroom climate and achievement motivation based on their father's occupation.

- There exists significant difference among higher secondary school students in their classroom climate and achievement motivation based on their mother's occupation.

\section{Conclusion}

Classroom climate and achievement plays the major role in teaching learning process. Achievement of students in the class is not only influenced by the motivation of the teachers but also by the positive classroom climate that prevails in the classrooms. The study has revealed that gender, medium of instruction, father's occupation played a significant role in their classroom climate and achievement motivation. The study has revealed that locality, mother's occupation do not play any significant role in their classroom climate and achievement motivation.

\section{References}

[1] Aggarwal, J.C. (1966). Educational research and introduction, Arya Book Depot: New Delhi.

[2] Chamundeswari, (2008). Journal of Educational research and extension, Ramakrishna mission vidyalaya college of Education, Coimbatore. (26 - 37).

[3] Golden, S. A. R. (2011). Problems and Prospectus of Distance Education. Quality Enhancement In Distance Education For Life Long Learning, 1(1), 343-344.

[4] Golden, S. A. R. (2016). RURAL STUDENTS' ATTITUDE TOWARDS ENGLISH AS MEDIUM OF INSTRUCTION IN HIGHER EDUCATION - AN ANALYSIS. International Journal of Research, 3(Special Issue - 16), 1-10.

[5] Golden, S. A. R. (2017). Recent Research In Social Science \& Humanities.

[6] Hourani, Sernak, Manoharan and Burton (2009). From competing commitments to informed choice: improving academic press and communication classroom climate.

[7] Indumati, T.(2015). "Study of Achievement motivation among adolescents". Edu Tracks. Vol.14, No.12, PP.17. 
[8] Pandy K. and Pratap T. (2001). Caste Belongingness and adjustment of high school girls. Indian psychological review, 56, 46-50.

[9] Regi, S. B., \& Golden, S. A. R. (2014). A Study On Educational Loan Availed By Students In Trichy City. JOURNAL OF INTERNATIONAL ACADEMIC RESEARCH FOR MULTIDISCIPLINARY (JIARM), 2(1).

[10] Suvin. (2009). Classroom climate on the Academic achievement of higher secondary school students, unpublished M.Ed. dissertation Tamilnadu Teacher education University Chennai.

[11] Uma, V.I (2008). Achievement motivation and Classroom climate among Students at Higher Secondary School level. Journal of Educational Research and Extension 45 (2) (0973-6190). 